\title{
Review and Assessment of the Effect of Hydrogen Gas Pressure on the Embrittlement of Steels in Gaseous Hydrogen Environment
}

\author{
Thorsten Michler*(D), Ken Wackermann and Frank Schweizer \\ Fraunhofer Institute for Mechanics of Materials, Woehlerstrasse 11, 79108 Freiburg, Germany; \\ ken.wackermann@iwm.fraunhofer.de (K.W.); frank.schweizer@iwm.fraunhofer.de (F.S.) \\ * Correspondence: thorsten.michler@iwm.fraunhofer.de
}

Citation: Michler, T.;

Wackermann, K.; Schweizer, F. Review and Assessment of the Effect of Hydrogen Gas Pressure on the Embrittlement of Steels in Gaseous Hydrogen Environment. Metals 2021, 11, 637. https://doi.org/10.3390/ met11040637

Academic Editor: Seok Su Sohn

Received: 3 March 2021

Accepted: 24 March 2021

Published: 14 April 2021

Publisher's Note: MDPI stays neutral with regard to jurisdictional claims in published maps and institutional affiliations.

Copyright: (c) 2021 by the authors. Licensee MDPI, Basel, Switzerland. This article is an open access article distributed under the terms and conditions of the Creative Commons Attribution (CC BY) license (https:// creativecommons.org/licenses/by/ $4.0 /)$.

\begin{abstract}
Hydrogen gas pressure is an important test parameter when considering materials for high-pressure hydrogen applications. A large set of data on the effect of hydrogen gas pressure on mechanical properties in gaseous hydrogen experiments was reviewed. The data were analyzed by converting pressures into fugacities $(f)$ and by fitting the data using an $f^{|n|}$ power law. For 95\% of the data sets, $|n|$ was smaller than 0.37 , which was discussed in the context of (i) rate-limiting steps in the hydrogen reaction chain and (ii) statistical aspects. This analysis might contribute to defining the appropriate test fugacities (pressures) to qualify materials for gaseous hydrogen applications.
\end{abstract}

Keywords: hydrogen embrittlement; gaseous hydrogen; pressure effect; steel

\section{Introduction}

Mobility based on hydrogen-powered vehicles such as fuel cell vehicles is a promising way to reduce greenhouse emissions. For high market penetration, the prognosis is that the costs of a hydrogen infrastructure are significantly lower compared to a battery-charging infrastructure [1]. However, there are special issues associated with the realization of a hydrogen infrastructure. One issue is the susceptibility of most structural materials, especially steels, to hydrogen embrittlement. Despite this issue, the overall goal is to realize safe and affordable infrastructure and mobility.

For automotives as well as for many infrastructure applications, the design must be safe, affordable and lightweight. The qualification of materials for use in hydrogen applications is specified in relevant standards. It is generally accepted that a material's qualification for gaseous hydrogen applications should be performed under conditions reflecting the final use of the material, i.e., in gaseous hydrogen atmospheres. Material testing in gaseous hydrogen atmospheres requires very specialized equipment [2,3] as well as strong safety protocols. Altogether, this results in high technological efforts, reflected by the costs being 15 to 150 times more expensive compared to tests in ambient air, depending on the test method (tensile test, crack growth test, etc.) [4]. Generating and maintaining a high hydrogen gas pressure throughout the test duration remains a technical challenge, especially at sub-ambient temperatures. The primary motivation of this study was to review the experimental data investigating the influence of external gas pressure on the degree of hydrogen effects in materials. The data were analyzed to quantify the effect of high hydrogen gas pressures of up to $100 \mathrm{MPa}$ on the mechanical properties of steels and to propose a rationale for the definition of test pressures for high-pressure hydrogen applications.

\section{Experimental and Analytical Details}

This study reviews the experimental results of the influence of external high-pressure hydrogen on the various mechanical properties of steels. This study only reviews the 
results obtained in gaseous hydrogen environments at room temperature, with a focus on hydrogen gas pressures of up to at least $70 \mathrm{MPa}$ (Table 1). Such experiments were typically performed with apparatuses similar to those described in [2,3]. Studies investigating the influence of hydrogen gas pressure at temperatures other than room temperature were not found in the existing literature. Only results obtained by the hydrogen pre-charging of steels (gaseous or electrochemical) simulating external high hydrogen gas pressures were used to interpret the results.

Since the effect of hydrogen on the mechanical properties of steels typically increases with increasing hydrogen gas pressure $(p)$, resulting in increased hydrogen concentration (c) [5-7], the experimental data must be fitted using an equation reflecting the rate-limiting steps in environmental hydrogen experiments. Such rate-limiting steps are [8]:

1. Transport of hydrogen to the crack tip, proportional to $p$;

2. Physical adsorption, proportional to $p$;

3. Dissociative chemical adsorption, proportional to $p^{0.5}$;

4. Hydrogen absorption, Sievert's law, proportional to $p^{0.5}$;

5. Transport of hydrogen to regions of tensile stress, not dependent on $p$;

6. Hydrogen-material interactions, not dependent on $p$.

At high pressures (and low temperatures), the behavior of a gas deviates from that of an ideal gas. The appropriate thermodynamic parameter is fugacity $(f)$, which is correlated to the pressure according to

$$
f=p e^{\frac{p b}{R T}}
$$

with $b=$ constant, $R=$ universal gas constant, and $T=$ temperature [9]. The correlation between pressure and fugacity is shown in Figure 1a. At room temperature, $f \approx p$ for pressures lower than $1 \mathrm{MPa}$, which is known as Sievert's law. For higher pressures, the non-ideal gas behavior must be considered especially in the power laws of rate limiting steps 3 and 4 . Using Sievert's law as an example, $p^{0.5}$ translates to $f^{0.5}$ [9].

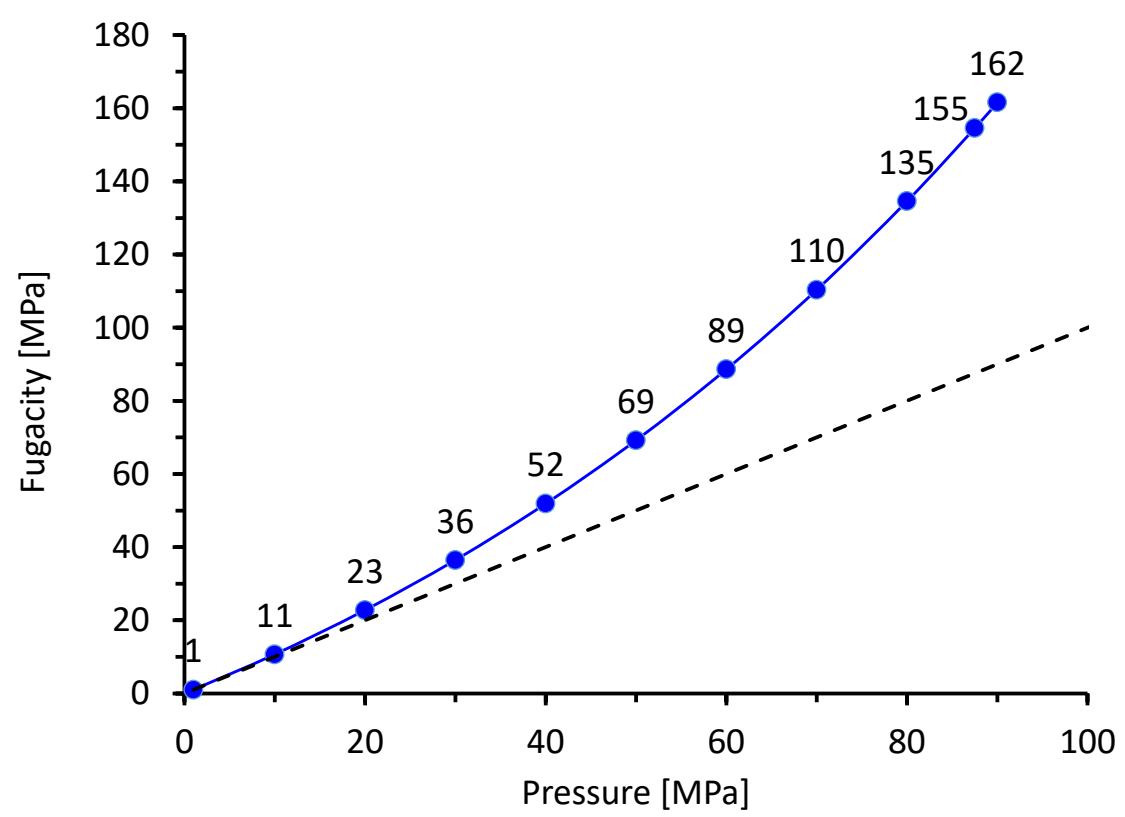

Figure 1. Correlation between pressure and fugacity at room temperature calculated by Equation (1).

In the following, the data were analyzed in terms of fugacity instead of pressure. Based on this analysis, the experimental data were fitted using the following equation:

$$
H E I \sim m f^{n}
$$


where $H E I=$ any hydrogen embrittlement index, $m=$ the factor and $n=$ the exponent. Typical hydrogen embrittlement indices use the ratio of the mechanical property measured in $\mathrm{H}_{2}$ and in air, in percent. In this review, the relative fracture toughness $\left(\mathrm{K}_{\mathrm{H} 2} / \mathrm{K}_{\mathrm{air}}\right)$, relative crack growth rate $\left(\mathrm{da} / \mathrm{dN}_{\mathrm{H} 2} / \mathrm{da} / \mathrm{dN}_{\mathrm{air}}\right)$, relative reduction of area $\left(\mathrm{RRA}=\mathrm{RA}_{\mathrm{H} 2} / \mathrm{RA}_{\mathrm{air}}\right)$ of the tensile specimens and the relative number of cycles to the failure $\left(\mathrm{N}_{\mathrm{f}_{-} \mathrm{H} 2} / \mathrm{N}_{\mathrm{f}_{-} \text {air }}\right)$ of fatigue life tests were calculated based on the published experimental data. In most references, the mechanical property in the control atmosphere (in most cases, air) was not measured as a function of pressure. In other words, the value measured in ambient air was used to calculate the embrittlement index for all hydrogen fugacities. Using such indices, the degree of embrittlement increases as the index decreases, except for the crack growth tests, because crack growth is accelerated in hydrogen compared to air. The experimental data were fitted using the method of least squares. The most important experimental details of the results reviewed here are summarized in Table 1, including the fit exponent $(n)$ from Equation (2), as well as the coefficient of determination $\left(R^{2}\right)$. Further details can be found in the respective references.

\section{Results}

Figure 2 shows the quasi-static properties, i.e., the relative reduction of area (RRA) of the tensile specimens for heat-treatable steels (Figure 2a,b), carbon steels (Figure 2c) and austenitic stainless steels (Figure 2d,e), as well as the relative fracture toughness (relative $\mathrm{K}$ ) of heat-treatable and low alloyed steels (Figure 2f,g) as a function of hydrogen fugacity. Microstructures, tensile properties in air, fit parameters according to Equation (2), as well as the coefficient of determination $\left(R^{2}\right)$, are summarized in Table 1 . All experimental data were fitted using Equation (2) with a reasonably high $R^{2}$ value greater than approximately 0.6 . For most of the data, the $R^{2}$ value was greater than 0.8 . The analysis of the absolute value of the fit exponent reveals a range of $|n|$ between approximately 0.05 and 0.3 .

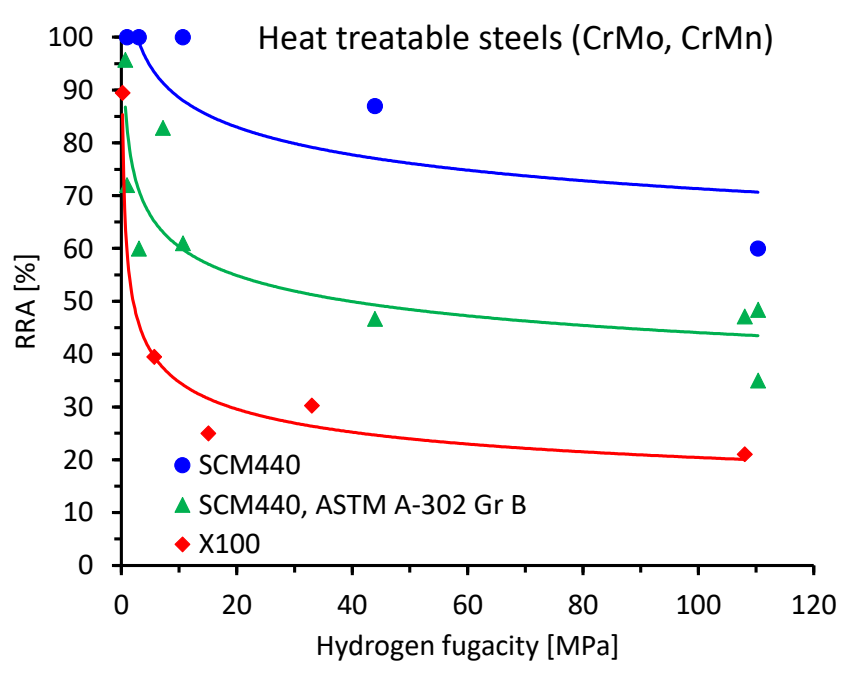

(a)

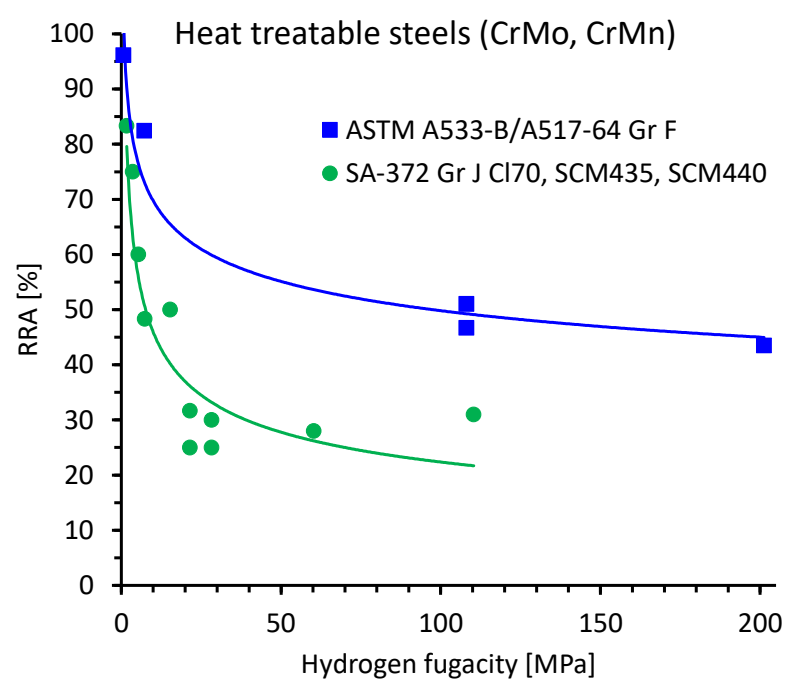

(b)

Figure 2. Cont. 


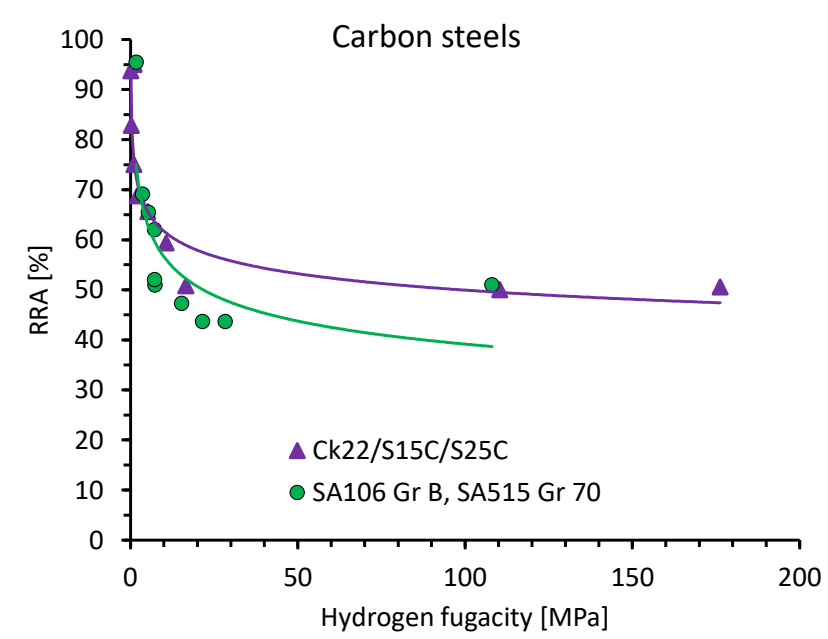

(c)

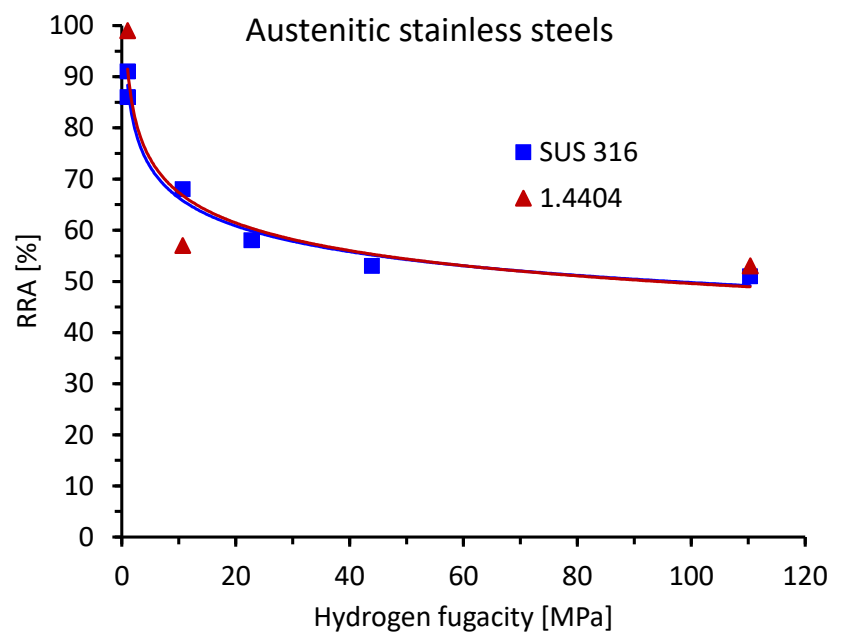

(e)

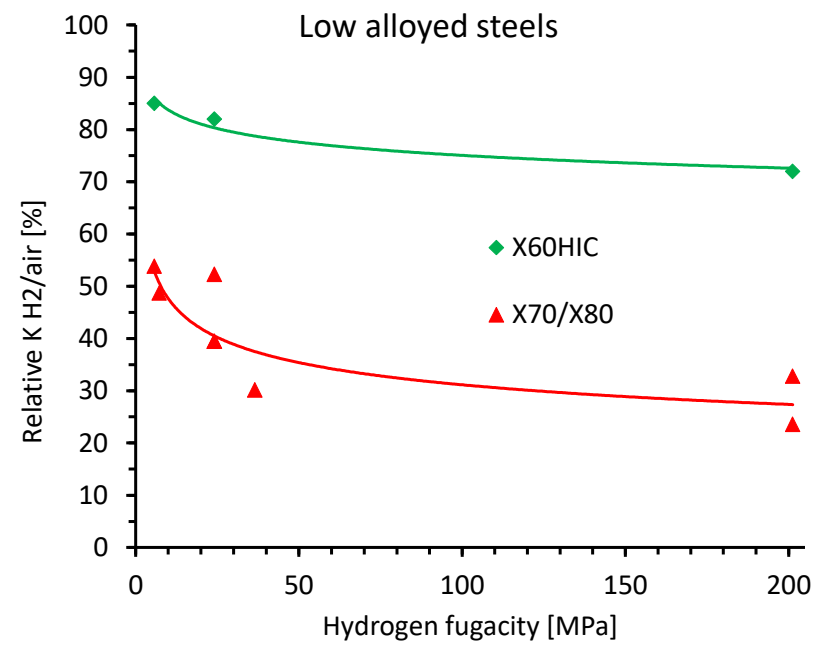

(g)

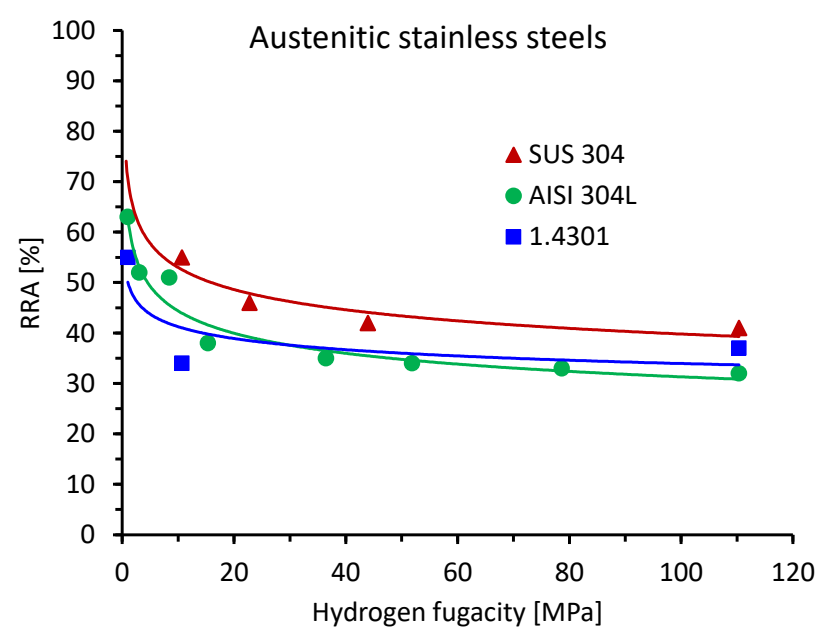

(d)

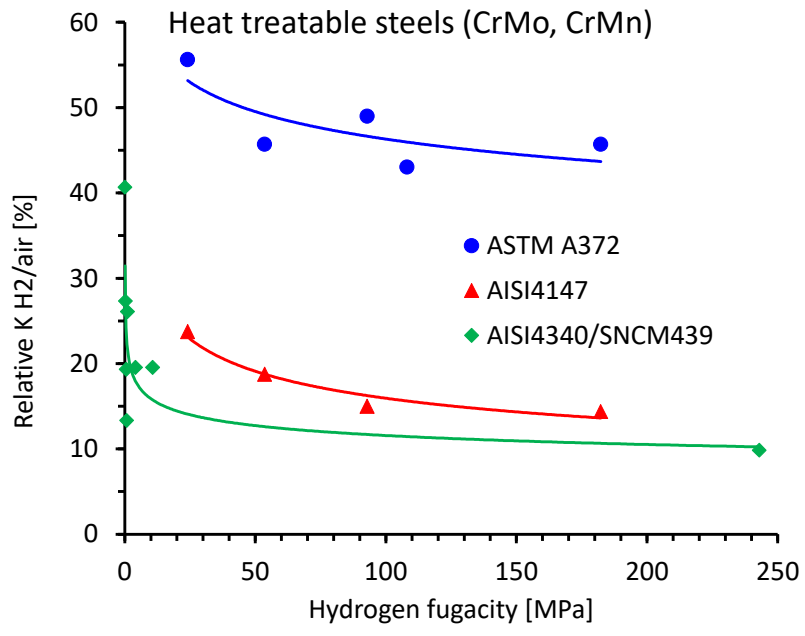

(f)

Figure 2. Results of the quasi-static tensile and fracture toughness tests as a function of hydrogen fugacity. Relative reduction of area (RRA) in the tensile tests for $(\mathbf{a}, \mathbf{b})$ heat-treatable steels, (c) carbon steels, $(\mathbf{d}, \mathbf{e})$ austenitic stainless steels. Relative fracture toughness of (f) heat-treatable steels, (g) low alloyed pipeline steels. References, test details and fit parameters are given in Table 1. 
Figure 3 summarizes the cyclic properties as a function of hydrogen fugacity, i.e., the relative crack growth rates (relative da/dN) for carbon steels (Figure 3a), heat-treatable steels (Figure 3b) and pure iron (Figure 3c), as well as the relative number of cycles to the failure of heat-treatable steels (Figure 3d). It should be noted here that the trend for the X80 pipeline steel was extrapolated (Figure 3d). Extrapolation of trends is generally associated with a high risk. However, the relative $\mathrm{N}_{\mathrm{f}}$ at a fugacity of $8 \mathrm{MPa}$ was already at a very low value of 0.1 and a significant further reduction in $\mathrm{N}_{\mathrm{f}}$ with increasing fugacity was not expected. This allowed a meaningful extrapolation of the trend for this specific data set. Cyclic data systematically studying the influence of pressure for austenitic stainless steels were not found in the existing literature, but results in [10] suggest a negligible influence between 10 and $103 \mathrm{MPa}$. All data in Figure 3 were fitted using Equation (2) with a reasonably high $R^{2}$ value greater than 0.55 . For most of the data, the $R^{2}$ value was greater than 0.9. The two different results for carbon steel SM490B were remarkable and even surprising (Figure 3a). Although the reported mechanical properties of the steels were very similar and the test conditions were identical (Table 1), significantly different crack growth rates were reported. A reason for this discrepancy could not be identified based on the available information in the respective references. Most relative da/dN values were calculated at $\Delta \mathrm{K} \approx 25 \mathrm{MPa} \mathrm{m}^{0.5}$. For steel HY-100, the data were acquired at $\Delta \mathrm{K}=55 \mathrm{MPa} \mathrm{m}{ }^{0.5}$ (Figure $3 \mathrm{~b}$ ). Quasi-static fracture toughness values between 30 and $80 \mathrm{MPa} \mathrm{m}^{0.5}$ measured in high-pressure hydrogen were reported in [11] for steels with similar tensile properties. In other words, the cyclic stress intensity range of $\Delta \mathrm{K}=55 \mathrm{MPa} \mathrm{m}^{0.5}$ might be close to the fracture toughness of HY-100 and the increasing relative da/dN values for fugacities higher than $100 \mathrm{MPa}$ might be explained by approaching the transition region to unstable crack growth at such high fugacities. For the cyclic data sets, the analysis of the absolute value of the fit exponent revealed a range of $|n|$ between approximately 0.08 and 0.4. (Table 1). Based on this analysis, the $|n|$ values for cyclic tests and quasi-static tests are in the same range (Table 1).

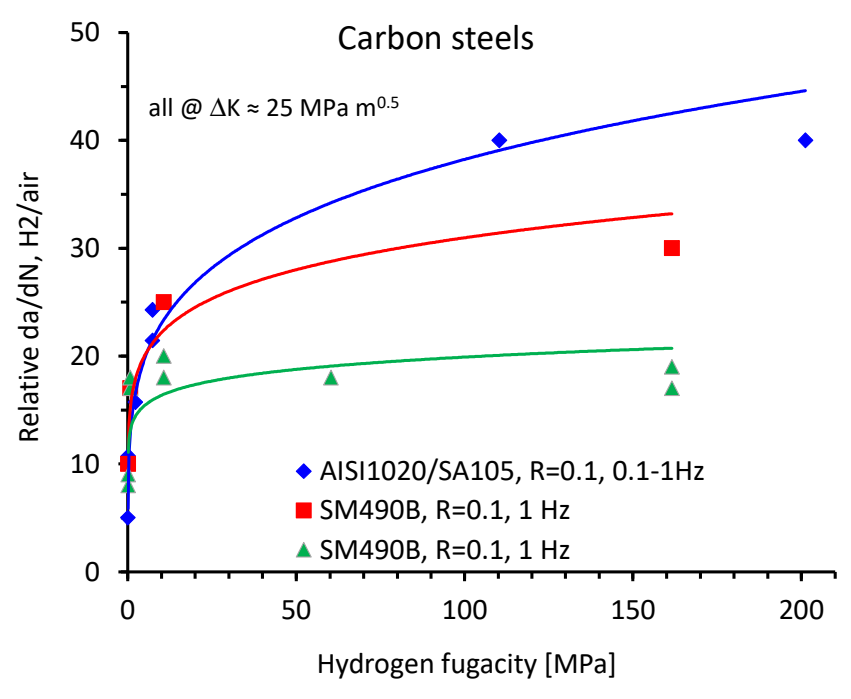

(a)

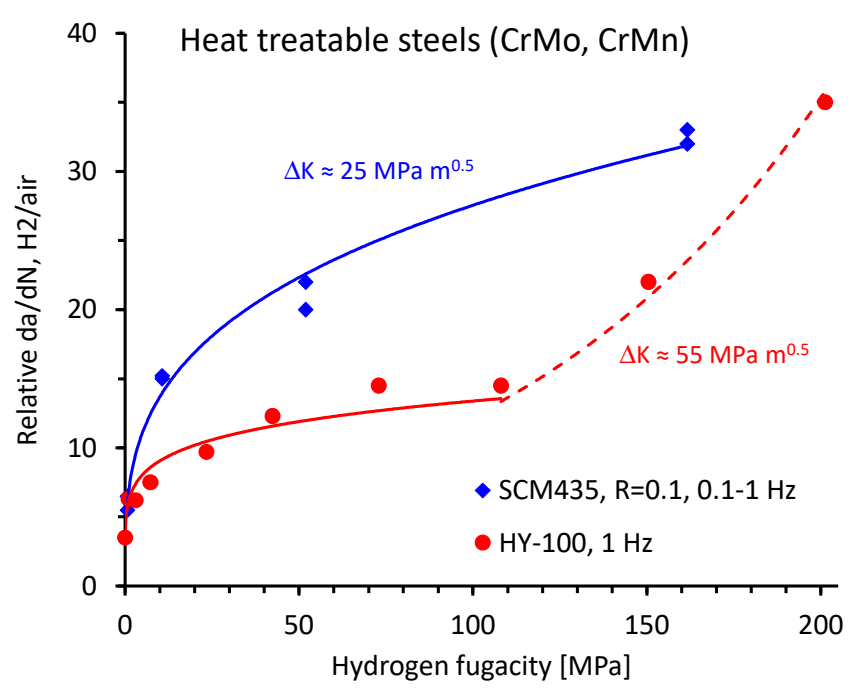

(b)

Figure 3. Cont. 


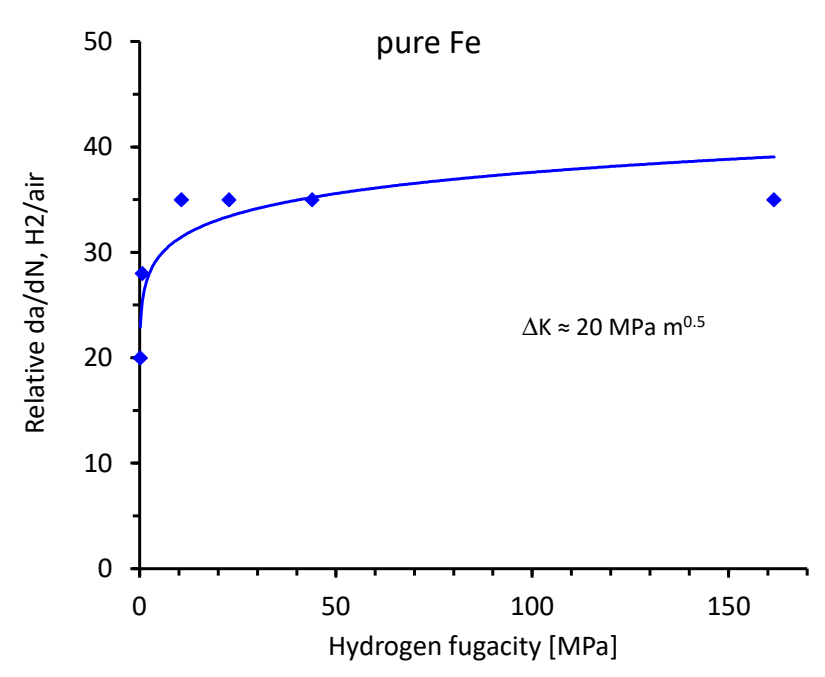

(c)

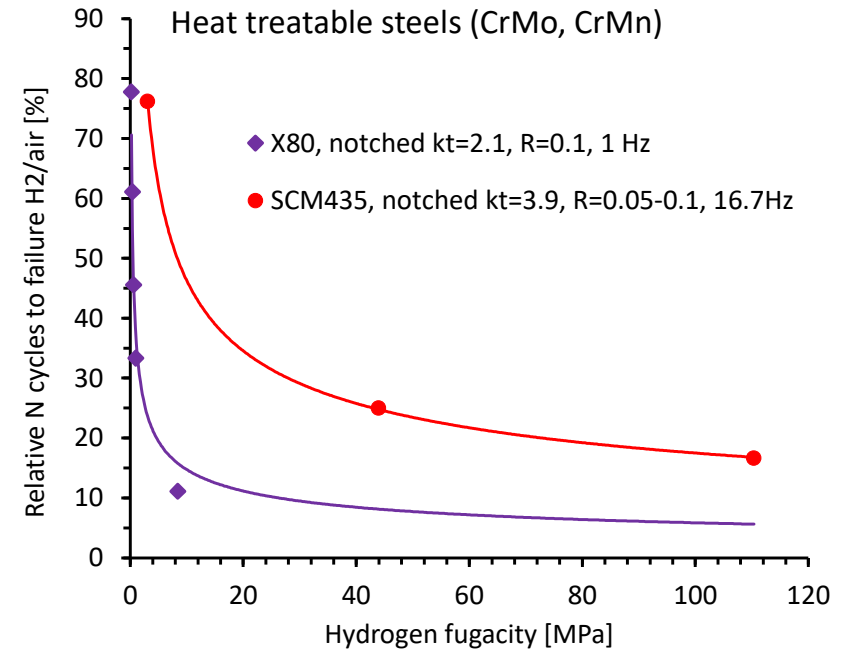

(d)

Figure 3. Results of the cyclic crack growth tests $(\mathrm{da} / \mathrm{dN})$ and fatigue life tests measuring the number of cycles to failure $\left(\mathrm{N}_{\mathrm{f}}\right)$ as a function of hydrogen test pressure. Relative da/dN for (a) carbon steels, (b) heat-treatable steels and (c) pure iron. (d) Relative number of cycles to the failure of heat-treatable steels. References, test details and fit parameters are given in Table 1. 


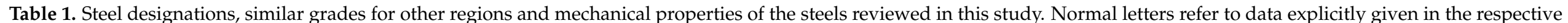

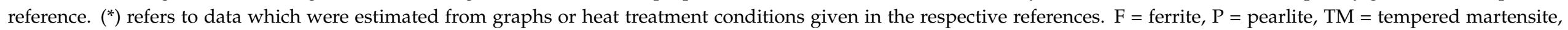
$\mathrm{B}=$ bainite, $\mathrm{AF}=$ acicular ferrite. $\mathrm{N}_{\mathrm{f}}=$ number of cycles to failure in Wöhler-type fatigue life tests, $\mathrm{K}=$ fracture toughness, da $/ \mathrm{dN}=\mathrm{crack}$ growth rate, na $=$ not annotated .

\begin{tabular}{|c|c|c|c|c|c|c|c|c|c|c|c|}
\hline \multirow{2}{*}{ Ref. } & \multicolumn{2}{|c|}{ Steel Designation } & \multirow{2}{*}{$\begin{array}{c}\text { Micro- } \\
\text { Structure * }\end{array}$} & \multicolumn{4}{|c|}{ Tensile Properties in Air } & \multirow{2}{*}{$\begin{array}{c}\text { Mechanical Property } \\
\text { Tested in } \mathrm{H}_{2}\end{array}$} & \multicolumn{3}{|c|}{ Fit Parameter } \\
\hline & As Given in Ref. & Equiv. Grades * & & YS, MPa & UTS, MPa & $E_{f}, \%$ & RA, \% & & m & n & $R^{2}$ \\
\hline [12] & Ck22 normalized & 1.1151, AISI 1022, S22C & $\mathrm{F}(+\mathrm{P})$ & $350 *$ & 531 & 32 & 64 & tensile RA & \multirow{5}{*}{76,236} & \multirow{5}{*}{-0.0920} & \multirow{5}{*}{0.8435} \\
\hline [13] & S15C & 1.1141, AISI 1015 & $\mathrm{~F}(+\mathrm{P})$ & $320 *$ & $490 *$ & $32 *$ & $68 *$ & tensile RA & & & \\
\hline [14] & S15C & 1.1141, AISI 1015 & $\mathrm{~F}(+\mathrm{P})$ & na & na & na & $\mathrm{Na}$ & tensile RA & & & \\
\hline [15] & S25C & 1.1158, AISI 1025 & $\mathrm{~F}(+\mathrm{P})$ & 334 & 547 & 31 & 72 & tensile RA & & & \\
\hline [16] & S25C & 1.1158, AISI 1025 & $\mathrm{~F}(+\mathrm{P})$ & 289 & 463 & na & 63 & tensile RA & & & \\
\hline [17] & ASME SA-106 Gr B & 1.0352, SFVC 1 & $\mathrm{~F}+\mathrm{P}$ & 297 & 518 & 28 & 70 & tensile RA & 81,863 & -0.1600 & 0.5871 \\
\hline$[19,20]$ & SCM440 & 1.7225, AISI4140 & $\mathrm{F}+\mathrm{P}$ & $350 *$ & $620 *$ & $23 *$ & $49 *$ & tensile RA & 110,000 & -0.0940 & 0.6595 \\
\hline [21] & ASTM A-302 Gr B & 1.5414, SBV 1 B & $\mathrm{TM}$ & $550 *$ & 813 & 28 & 70 & tensile RA & \multirow{2}{*}{82,568} & \multirow{2}{*}{-0.1360} & \multirow{2}{*}{0.7540} \\
\hline$[19,20]$ & SCM440 & 1.7225, AISI4140 & TM & $550 *$ & $980^{*}$ & $15^{*}$ & $35^{*}$ & tensile RA & & & \\
\hline$[22,23]$ & ASTM A533-B & 1.6311, SOV 2 B & $\mathrm{TM}$ & 703 & 786 & 20 & 69 & tensile RA & \multirow{2}{*}{97,583} & \multirow{2}{*}{-0.1460} & \multirow{2}{*}{0.9530} \\
\hline [24] & ASTM A-517-64 Gr F (T-1) & 1.8881, SEV 245 & $\mathrm{TM}$ & 751 & 813 & 25 & 66 & tensile RA & & & \\
\hline [17] & ASME SA-372 Gr J & 1.7225, SCM 440 & $\mathrm{TM}$ & $725 *$ & 883 & 20 & 60 & tensile RA & \multirow{3}{*}{94,268} & \multirow{3}{*}{-0.3120} & \multirow{3}{*}{0.7636} \\
\hline [25] & SCM435 & 1.7220, AISI 4130 & TM & $770 *$ & $873^{*}$ & $14^{*}$ & $56^{*}$ & tensile RA & & & \\
\hline [14] & SCM440 & 1.7225, SA-372 Gr J, AISI 4140 & $\mathrm{TM}$ & $\mathrm{Na}$ & na & $\mathrm{Na}$ & na & tensile RA & & & \\
\hline [27] & SUS304 & 1.4301, AISI304 & $\mathrm{A}$ & $\mathrm{Na}$ & na & na & na & tensile RA & 62,878 & -0.1510 & 0.9459 \\
\hline [28] & AISI 304L & 1.4306, SUS 304L & A & $250 *$ & $550 *$ & $60 *$ & na & tensile RA & 70,536 & -0.1240 & 0.8557 \\
\hline [29] & 1.4301 & AISI304, SUS304 & $\mathrm{A}$ & 211 & 589 & 90 & 85 & tensile RA & 50,123 & -0.0850 & 0.9459 \\
\hline [29] & 1.4404 & AISI316, SUS316 & $\mathrm{A}$ & 201 & 575 & 81 & 84 & tensile RA & 91,568 & -0.1330 & 0.8383 \\
\hline [11] & ASTM A372 & 1.7225, SCM440 & $\mathrm{TM}$ & 586 & 813 & 19 & 49 & K & 72,392 & -0.0970 & 0.5786 \\
\hline [11] & AISI 4147 & 1.7225, SCM445 & TM & 869 & 1007 & 19 & 61 & $\mathrm{~K}$ & 53,047 & -0.2610 & 0.9374 \\
\hline [30] & AISI 4340 & 1.6511, SNCM439 & TM & 1234 & 1338 & 14 & 46 & K & \multirow{3}{*}{21,861} & \multirow{3}{*}{-0.1380} & \multirow{3}{*}{0.632} \\
\hline [31] & SNCM439 & 1.6511, AISI4340 & $\mathrm{TM}$ & 1230 * & 1344 & $15^{*}$ & $45 *$ & $\mathrm{~K}$ & & & \\
\hline [32] & SNCM439 & 1.6511, AISI4340 & $\mathrm{TM}$ & 1147 & 1201 & 18 & 59 & $\mathrm{~K}$ & & & \\
\hline [33] & $\mathrm{X} 80$ & 1.8758 & $\mathrm{~F}+\mathrm{B} / \mathrm{AF}$ & 595 & 705 & 24 & na & $\mathrm{N}_{\mathrm{f}}$ & 37,051 & -0.400 & 0.9556 \\
\hline [34] & SCM435 & 1.7220, AISI 4130 & $F+P$ & $360^{*}$ & $540 *$ & $17^{*}$ & $78^{*}$ & $\mathrm{~N}_{\mathrm{f}}$ & 122,510 & -0.4230 & 0.9999 \\
\hline
\end{tabular}


Table 1. Cont

\begin{tabular}{|c|c|c|c|c|c|c|c|c|c|c|c|}
\hline \multirow{2}{*}{ Ref. } & \multicolumn{2}{|c|}{ Steel Designation } & \multirow{2}{*}{$\begin{array}{c}\text { Micro- } \\
\text { Structure }\end{array}$} & \multicolumn{4}{|c|}{ Tensile Properties in Air } & \multirow{2}{*}{$\begin{array}{l}\text { Mechanical Property } \\
\text { Tested in } \mathbf{H}_{2}\end{array}$} & \multicolumn{3}{|c|}{ Fit Parameter } \\
\hline & As Given in Ref. & Equiv. Grades * & & YS, MPa & UTS, MPa & $E_{f}, \%$ & RA, \% & & $\mathbf{m}$ & $\mathbf{n}$ & $R^{2}$ \\
\hline [35] & AISI 1020 & $1.1151, \mathrm{~S} 20 \mathrm{C}$ & $\mathrm{F}(+\mathrm{P})$ & 207 & 379 & na & na & $\mathrm{da} / \mathrm{dN}$ & \multirow{2}{*}{13,860} & \multirow{2}{*}{0.2203} & \multirow{2}{*}{0.0942} \\
\hline [36] & ASME SA105 Gr 2 & 1.0460 & $\mathrm{~F}+\mathrm{P}$ & 269 & 462 & 33 & 63 & $\mathrm{da} / \mathrm{dN}$ & & & \\
\hline [37] & SM490B & $1.0545, \mathrm{~K} 12000$ & $F+P$ & 360 & 537 & na & na & $\mathrm{da} / \mathrm{dN}$ & 15,878 & 0.1451 & 0.9248 \\
\hline [38] & SM490B & $1.0545, \mathrm{~K} 12000$ & $F+P$ & 360 & 540 & 17 & 78 & $\mathrm{da} / \mathrm{dN}$ & 13,446 & 0.0851 & 0.5481 \\
\hline [39] & SCM435 & 1.7220, AISI 4130 & TM & 700 & 828 & na & 72 & $\mathrm{da} / \mathrm{dN}$ & 6811 & 0.3035 & 0.9859 \\
\hline [23] & HY-100 & 1.6742, SFVQ 3 & $\mathrm{TM}$ & 758 & 855 & 25 & 70 & $\mathrm{da} / \mathrm{dN}$ & 6130 & 0.1696 & 0.9456 \\
\hline [44] & $\mathrm{X} 100$ & - & B & 679 & 802 & 22 & 76 & tensile RA & 58,951 & -0.2300 & 0.9394 \\
\hline [45] & X70/X80 heat $B$ & 1.8758 & $\mathrm{~F}+\mathrm{P}$ & 565 & 600 & na & na & $\mathrm{K}$ & \multirow{5}{*}{72,923} & \multirow{5}{*}{-0.1850} & \multirow{5}{*}{0.7091} \\
\hline [46] & X80 heat $\mathrm{E}$ & 1.8758 & $\mathrm{~F}+\mathrm{P}$ & 593 & 710 & 36 & na & K & & & \\
\hline [46] & X80 heat $F$ & 1.8758 & $F+P$ & 552 & 696 & 34 & na & K & & & \\
\hline [47] & $\mathrm{X70}$ & 1.8758 & $\mathrm{~F}+\mathrm{P}$ & 584 & 669 & 20 & 57 & K & & & \\
\hline [48] & X80 & 1.8758 & $F+P$ & 510 & 689 & na & na & K & & & \\
\hline [45] & X60HIC & 1.8973 & $F+P$ & 434 & 486 & na & na & K & 95,104 & 0.0570 & 0.9303 \\
\hline
\end{tabular}




\section{Discussion}

As mentioned previously, the experimental data were fitted using Equation (2). For $|n|=0.5$, all rate limiting steps (Figure 4 ) would be undistorted. However, the analysis performed in this study shows that the influence of hydrogen fugacity upon the mechanical properties of steels does not follow a $f^{|0.5|}$ law for a wide variety of microstructures, strength levels, and test methods (Table 1).

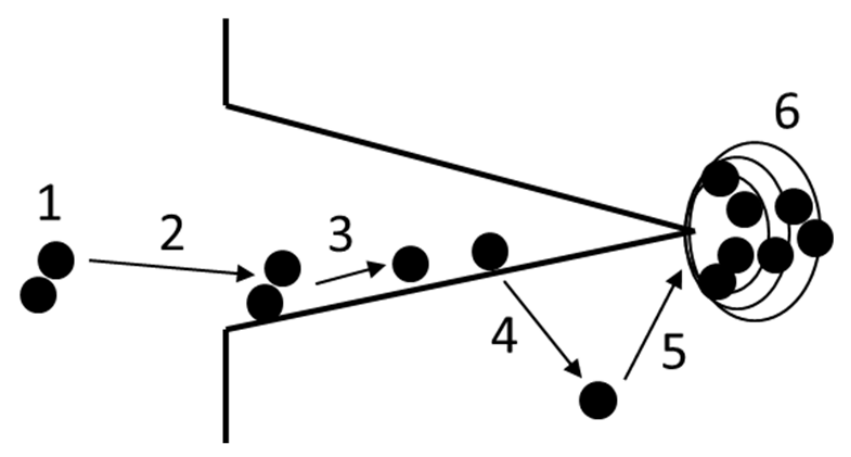

Figure 4. Rate-limiting steps for the transport of hydrogen to the fracture propagation zone. 1 = transport of hydrogen to the crack tip, 2 = physical adsorption, 3 = dissociative chemical adsorption, $4=$ hydrogen absorption, $5=$ transport of hydrogen to regions of tensile stress, $6=$ hydrogen-material interactions.

The first part of the discussion focuses on the possible rate-limiting steps in the hydrogen reaction chain (Figure 4). It is known that for metals loaded in a hydrogen gas environment, hydrogen-assisted crack initiation typically starts at the gas-metal interface. Upon further loading, this crack propagates into the material until a final cross-section fails by overload fracture. In other words, special attention must be paid to the possible rate-limiting steps at the gas-metal interface.

As outlined in [8], the collision rate of gas molecules with a metal surface is linearly proportional to the gas pressure, and a sticking coefficient of approximately 1 can be assumed for pure metal surfaces. Under such conditions, around one monolayer of $\mathrm{H}_{2}$ adsorbs within one second at a pressure of $10^{-10} \mathrm{MPa}$ hydrogen partial pressure. With this estimation, it appears very unlikely that Steps 1 and 2 (the transport of hydrogen to the crack tip and physical adsorption) are rate-controlling under the test conditions discussed in this study with fugacities up to approximately $250 \mathrm{MPa}$.

The role of dissociative chemical adsorption was discussed in detail in [49]. It was shown that on Fe and Ni single-crystal surfaces, the coverage of dissociative sites is $100 \%$ at hydrogen gas pressures in the order of $10^{-1} \mathrm{MPa}$. Whether this is also true for highly distorted poly-crystals along a crack surface has not been investigated so far [8]. However, when considering fugacities up to approximately $250 \mathrm{MPa}$, it appears unlikely that dissociative chemical adsorption is rate-limiting under the test conditions discussed in this study.

The role of hydrogen absorption can be assessed by comparing test results obtained in gaseous hydrogen atmospheres with those of hydrogen pre-charged specimens. Hydrogen pre-charging of materials is typically performed under charging conditions to ensure a homogeneously saturated microstructure, and it appears that the fugacity-modified Sievert's law accurately predicts the hydrogen concentration in austenitic stainless steels pre-charged at high fugacities (Figure 5a). This method eliminates Steps 1 to 4 from the reaction chain (Figure 4). However, the analysis of data obtained with hydrogen precharged materials (Figure $5 b$ ) reveals $|n|$ values in the same range as obtained with tests in gaseous hydrogen atmosphere being significantly lower than 0.5 . Since this trend does not change after eliminating Step 4 from the reaction chain, it is unlikely that hydrogen absorption is a primary rate-limiting step when testing in gaseous hydrogen atmospheres. 


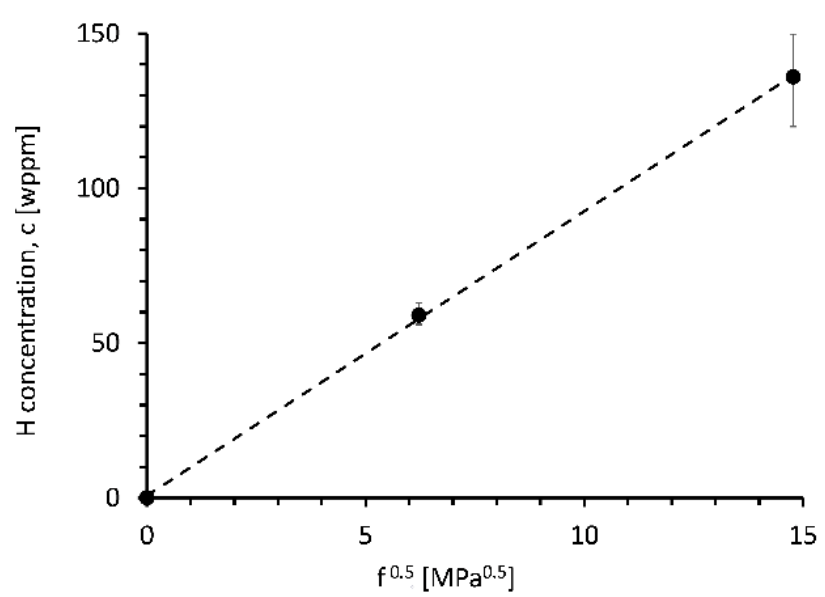

(a)

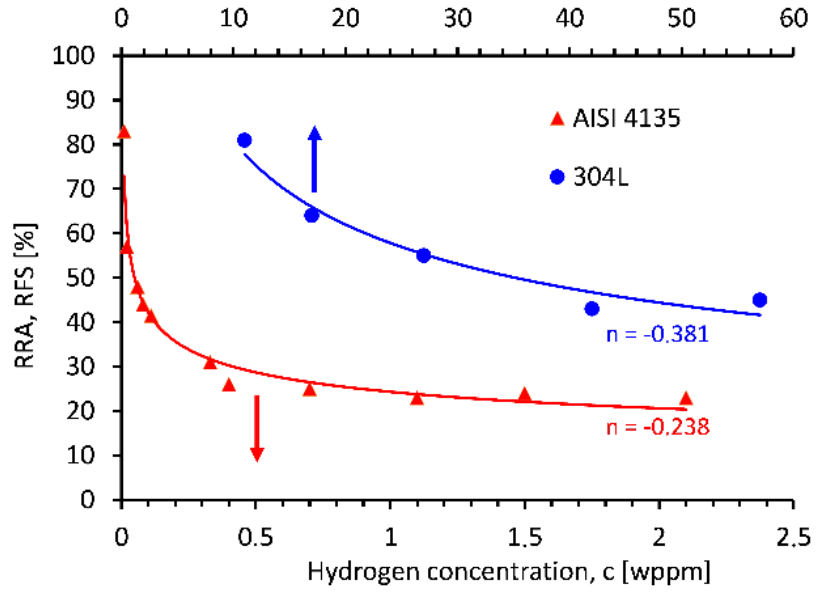

(b)

Figure 5. (a) Fugacity-modified Sievert's law with data from [50,51], (b) RRA of 304 L austenitic stainless steel [5] and relative fracture stress (RFS) of AISI 4135 martensitic high strength steel [7] pre-charged with hydrogen as a function of hydrogen concentration.

Although not fugacity-dependent rather than microstructure-dependent, the transport of hydrogen to regions of tensile stress, i.e., the crack tip, can also be rate-limiting. Hydrogen transport over distances larger than a few grain diameters is controlled by bulk Fickian diffusion, characterized by the diffusivity $D$. The diffusivities at room temperature are in the order of $10^{-15}$ to $10^{-16} \mathrm{~m}^{2} / \mathrm{s}$ for face cubic centered (fcc) austenitic stainless steels [9] and $10^{-8} \mathrm{~m}^{2} / \mathrm{s}$ to $10^{-11} \mathrm{~m}^{2} / \mathrm{s}$ for body cubic centered (bcc) steels depending on the microstructure $[52,53]$. Although the diffusivities of bcc steels and austenitic steels differ by several orders of magnitude, a significant difference in their mechanical response as a function of fugacity could not be identified (Figure 2). In other words, if $D$ were a primary rate-controlling parameter (at temperatures around room temperature), the fucacity dependence of the HEI data of bcc and fcc austenitic steels should be clearly different, which is not the case. Therefore, it appears unlikely that hydrogen bulk diffusivity is a primary rate-limiting parameter when testing in a gaseous hydrogen atmosphere.

If Steps 1 to 5 of the hydrogen reaction chain are not rate-limiting, then the mechanisms involved in the hydrogen-material interactions (Step 6) must control the hydrogen embrittlement effects. The length scale is in the order of the plastic zone in front of a flaw or crack tip, typically around a few 10 to a few $100 \mu \mathrm{m}$. Although the size of this zone comprises several grain diameters, the mechanisms are dominated by the so-called strain rate factor of the hydrogen transport equation, which is not a function of $D$ [54-56]. There is experimental evidence that hydrogen influences dislocation motion and it can fairly be assumed that this effect increases with increasing local hydrogen concentration around the dislocation core. In this case, the interaction of hydrogen with dislocations plays a predominant role $[8,57,58]$. Unfortunately, currently, such mechanisms are not understood at the level of detail to quantify such effects. However, modern simulation tools may provide a framework to study such effects, since a model based on hydrogen accumulation and transport around a micro-crack using embedded atom methods and density functional theory calculations showed promising results [59].

The second part of the discussion focuses on the selection of material test fugacities (pressures) for high-pressure hydrogen applications. Figure 6a shows a histogram of the fit exponents $(|n|)$ from Table 1, which suggests an asymmetric distribution. A statistical analysis revealed that these experimental data were well represented by a Weibull distribution. This appears reasonable because Weibull distributions are often found in statistics where values are bound to natural limits-here, $0 \leq|n| \leq 0.5$. The corresponding Weibull curves 
are shown in Figure $6 \mathrm{~b}$ with an expected $|n|$ value of approximately 0.12 and $95 \%$ of the $|n|$ values are lower than 0.37 .

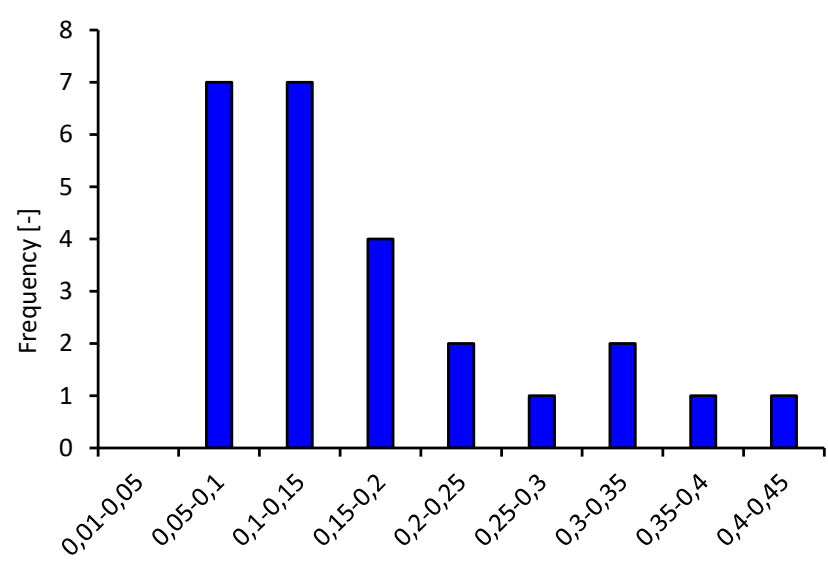

Fit exponent $|n|[-]$

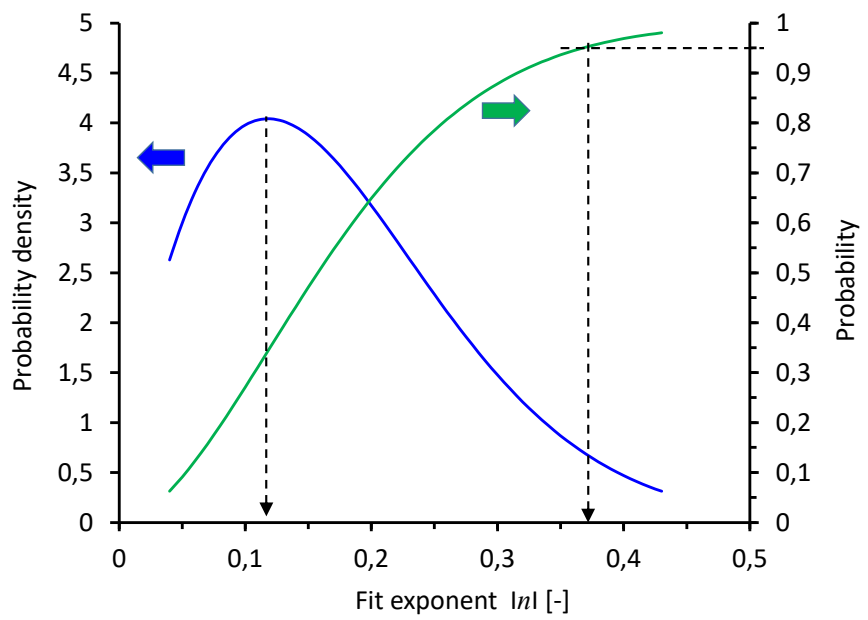

(b)

Figure 6. (a) Histogram of the fit exponents $(|n|)$ from Table 1, (b) corresponding Weibull curves, scale parameter 1.727, shape parameter 0.195 , coefficient of determination $R^{2}=0.895$.

The following discussion focuses on the two characteristic $|n|$ values, i.e., $|n|=0.12$ and $|n|=0.37$. To discuss the effect of these results on the definition of hydrogen test fugacities (pressures), two engineering applications were selected as use cases. The typical test pressure for automotive hydrogen tanks is $87.5 \mathrm{MPa}\left(f_{1}=155 \mathrm{MPa}\right)$ and the typical operating pressure of gas pipelines is $10 \mathrm{MPa}\left(f_{2}=11 \mathrm{MPa}\right)$. These nominal fugacities were used to calculate severity factors as

$$
S F_{1,2}=\left(\frac{f}{f_{1,2}}\right)^{n}, f<f_{1,2}
$$

using $|n|=0.12$ and $|n|=0.37$ (Figure 7). SF indicates how much less severe a test at $f$ is compared to the reference fugacities $f_{1}$ and $f_{2}$, respectively. For example, for $f_{1}=155 \mathrm{MPa}$ and $|n|=0.12$, the severity factor of SF $=0.94$ indicates that a fugacity of approximately $93 \mathrm{MPa}$ is less severe by a factor of 0.94 compared to a fugacity of $155 \mathrm{MPa}$ (Figure 7).

The severity factor of the fugacity can then be compared with the inherent variation in the measured mechanical property. Repeatability and reproducibility studies on high-pressure gaseous hydrogen's effects on the tensile properties of various structural materials $[60,61]$ revealed that when only considering the scatter of quasi-static tensile test results in a control atmosphere, the RRA value must be lower than 0.89 to 0.99 (89\% to $99 \%$ ), depending on the material, in order to account for this reduction in hydrogen effects with a $95 \%$ confidence level (Table 2). The average value of 0.94 is represented by the solid horizontal line in Figure 7. Using again $f_{1}=155 \mathrm{MPa}$ and $|n|=0.12$ as an example, the severity factor of $\mathrm{SF}=0.94$ indicates that a fugacity of approximately $93 \mathrm{MPa}$ is less severe by a factor of 0.94 compared to a fugacity of $155 \mathrm{MPa}$. However, the measured hydrogen effects lie within the scatter of the results in the control atmosphere and, thus, are not statistically relevant with a 95\% confidence level. In other words, for materials following an $f^{0.12}$ law, any hydrogen effects measured between 93 and $155 \mathrm{MPa}$ are not statistically relevant with a $95 \%$ confidence level. The lower bound fugacities for $f_{2}=11 \mathrm{MPa}$ and $|n|=0.37$ are given in Table 3 . This analysis may provide a data-based rationale for defining appropriate test fugacities (pressures) for high-pressure hydrogen applications. 


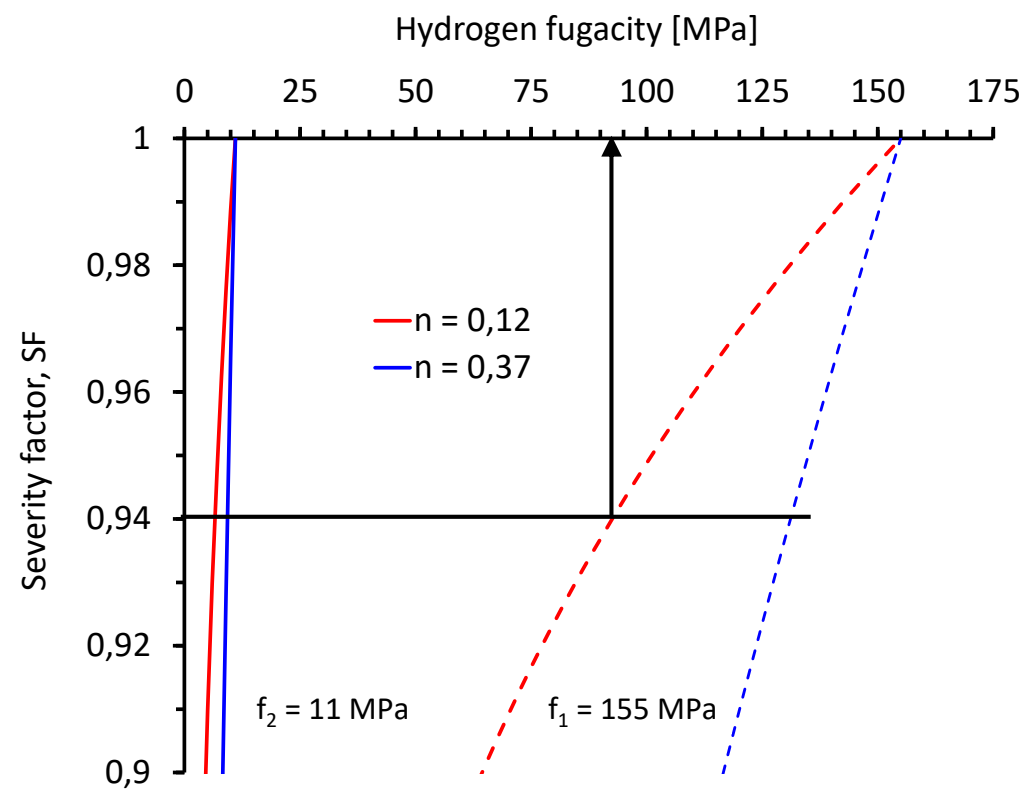

Figure 7. Severity factor (SF) quantifying the effect of hydrogen fugacity on hydrogen embrittlement indices assuming an $f^{n}$ law with $f_{1}=155 \mathrm{MPa}$ and $f_{2}=11 \mathrm{MPa}$ as use cases. For example, for $f_{1}=155 \mathrm{MPa}$ and $|n|=0.12$, the severity factor of $\mathrm{SF}=0.94$ indicates that a fugacity of approximately $93 \mathrm{MPa}$ is less severe by a factor of 0.94 compared to a fugacity of $155 \mathrm{MPa}$.

Table 2. Results of repeatability and reproducibility studies of tensile tests in ambient control atmospheres (helium, nitrogen or air). $\mathrm{RR}$ = round robin.

\begin{tabular}{cccccc}
\hline & A286 & Inconel 718 & AISI 4340 & SUS316L & $\mathbf{1 . 4 4 0 4}$ \\
\hline Tensile strength (MPa) & 1166 & 1401 & 1374 & 710 & 587 \\
\hline No of labs participating in RR & 6 & 6 & 6 & 3 & 1 \\
\hline No of specimens tested per lab & 3 & 3 & 3 & 3 & 10 \\
\hline RRA lower 95\% conficence & 0.94 & 0.89 & 0.93 & 0.99 & 0.98 \\
\hline Reference & {$[60]$} & {$[60]$} & {$[60]$} & {$[61]$} & own results \\
\hline
\end{tabular}

Table 3. Calculated lower bound fugacities (pressures) for $\mathrm{SF}=0.94$.

\begin{tabular}{ccc}
\hline$S F=0.94$ & $\begin{array}{c}f_{1}=155 \mathrm{MPa} \\
\left(\mathbf{p}_{\mathbf{1}}=87.5 \mathrm{MPa}\right)\end{array}$ & $\begin{array}{c}f_{2}=11 \mathrm{MPa} \\
\left(\mathbf{p}_{\mathbf{2}}=10 \mathrm{MPa}\right)\end{array}$ \\
\hline$n=0.12$ & $93(62)$ & $6.7(6.4)$ \\
\hline$n=0.35$ & $131(79)$ & $9.5(9.0)$ \\
\hline
\end{tabular}

\section{Summary}

The findings of this review can be summarized as follows:

- The relative reduction in mechanical properties in gaseous hydrogen experiments follows an $f^{|n|}$ power law ( $f=$ fugacity).

- The exponent $|n|$ was found to be smaller than 0.4. Since theoretical assumptions predict $n=0.5$ for a fully undistorted hydrogen reaction chain, the reviewed data are interpreted in a way that hydrogen-dislocation interactions are the rate-limiting step controlling hydrogen effects in steels.

- A statistical analysis of the reviewed data revealed that $95 \%$ of the $|n|$ values are lower than 0.37 .

- This analysis might be used to define appropriate test fugacities (pressures) to qualify materials for high-pressure gaseous hydrogen applications. 
Author Contributions: Conceptualization, T.M.; data curation, T.M.; writing-original draft preparation, T.M.; writing-review and editing, F.S. and K.W. All authors have read and agreed to the published version of the manuscript.

Funding: This research received no external funding.

Institutional Review Board Statement: Not applicable.

Informed Consent Statement: Not applicable.

Data Availability Statement: Not applicable.

Acknowledgments: The authors are grateful for their discussion with Christopher San Marchi from Sandia National Laboratories, Livermore, USA.

Conflicts of Interest: The authors declare no conflict of interest.

\section{References}

1. Robinius, M.; Linßen, J.; Grube, T.; Reuß, M.; Stenzel, P.; Syranidis, K.; Kuckertz, P.; Stolten, D. Comparative Analysis of Infrastructures: Hydrogen Fueling and Electric Charging of Vehicles. In Schriften des Forschungszentrums Jülich Reihe Energie E Umwelt/Energy E Environment Band/Volume 408; Forschungszentrum Jülich: Jülich, Germany, 2018; p. 127. ISBN 978-3-95806-295-5.

2. Deimel, P.; Hanisch, C. Tests on the steels $15 \mathrm{MnNi} 63$ and X56TM in high pressure hydrogen gas of high purity. Int. J. Hydrogen Energy 1989, 14, 147-151. [CrossRef]

3. Fukuyama, S.; Imade, M.; Yokogawa, K. Hydrogen and Evaluation of Hydrogen Gas Embrittlement of Metals. In Proceedings of the ASME 2008 Pressure Vessel and Piping Conference (PVP 2008), Chicago, IL, USA, 27-31 July 2008; ASME Press: San Antonio, TX, USA, 2008.

4. Vesely, E.J.; Bhat, B.N.; McPherson, W.B.; Grethlein, C.E. Reproducibility and repeatability of tensile and low cycle fatigue properties in propulsion grade hydrogen. In Proceedings of the 5th International Conference on the Effect of Hydrogen on the Behavior of Materials, Moran, WY, USA, 11-14 September 1994; Moody, N.R., Thompson, A.W., Ricker, R.E., Was, G.W., Jones, R.H., Eds.; The Minerals, Metals \& Materials Society: Moran, WY, USA, 1994; pp. 363-374.

5. Buckley, J.R.; Hardie, D. The effect of pre-straining and d-ferrite on the embrittlement of 304L stainless steel by hydrogen. Corros. Sci. 1993, 34, 93-107. [CrossRef]

6. Omura, T.; Kobayashi, K.; Miyahara, M.; Kudo, T. Effect of surface hydrogen contents on hydrogen embrittlement properties of stainless steels. Corros. Eng. 2006, 55, 747-759.

7. Wang, M.; Akiyama, E.; Tsuzaki, K. Effect of hydrogen on the fracture behavior of high strength steel during slow strain rate test. Corros. Sci. 2007, 49, 4081-4097. [CrossRef]

8. Borchers, C.; Michler, T.; Pundt, A. Effect of hydrogen on the mechanical properties of stainless steels. Adv. Eng. Mater. 2008, 10, 11-23. [CrossRef]

9. Marchi, C.S.; Somerday, B.P.; Robinson, S.L. Permeability, solubility and diffusivity of hydrogen isotopes in stainless steels at high gas pressures. Int. J. Hydrogen Energy 2007, 32, 100-116. [CrossRef]

10. San Marchi, C.; Gibbs, P.; Foulk, J.; Nibur, K. Fatigue life of austenitic stainless steels in hydrogen environments. In Proceedings of the 43rd MPA Seminar, Stuttgart, Germany, 11-12 October 2017.

11. Loginow, A.W.; Phelbs, E.H. Steels for seamless hydrogen pressure vessels. Corros. NACE 1975, 31, 404-412. [CrossRef]

12. Hofmann, W.; Rauls, W. Ductility of steel under the influence of external high pressure hydrogen. Weld. Res. Suppl. 1965, 5, 225-230.

13. Zhang, L.; Wen, M.; Fukuyama, S.; Yokogawa, K. Effect of Temperature on Hydrogen Environment Embrittlement of Carbon Steels at Low Temperatures. J. Jpn. Inst. Met. 2003, 67, 460-463. [CrossRef]

14. Fukuyama, S.; Imade, M.; Lin, Z.; Yokogawa, K. Hydrogen embrittlement of metals in 70 MPA hydrogen at room temperature. Am. Soc. Mech. Eng. Press. Vessel. Pip. Div. PVP 2005, 6, 493-497.

15. New Energy and Industrial Technology Development Organization (NEDO). 2011 Oil Refining Industry Security Measures Project. RED on Material Usage Standards Associated with Hydrogen Energy Utilization; National Institute of Advanced Industrial Science and Technology (AIST): Tsukuba, Japan, 2012.

16. Ogawa, Y.; Hino, M.; Nakamura, M.; Matsunaga, H. Pearlite-driven surface-cracking and associated loss of tensile ductility in plain-carbon steels under exposure to high-pressure gaseous hydrogen. Int. J. Hydrogen Energy 2020, 46, 6945-6959. [CrossRef]

17. Xu, K.; Rana, M. Tensile and Fracture Properties of Carbon and Low Alloy Steels in High Pressure Hydrogen. In Proceedings of the 2008 International Hydrogen Conference-Effects of Hydrogen on Materials, Jackson Lake Lodge, WY, USA, 7-10 September 2008; pp. 349-356.

18. Walter, R.J.; Chandler, W.T. Effects of high-pressure hydrogen on metals at ambient temperature. In NASA-R-7780-1; National Aeronautics and Space Administration: Huntsville, AL, USA, 1969; p. 328.

19. New Energy and Industrial Technology Development Organization (NEDO). Development for Safe Utilization and Infrastructure of Hydrogen. Common Base Technology Development Relating Hydrogen. The Study of Basic Properties of Materials for Hydrogen; The Japan Research and Development Center for Metals: Tokyo, Japan, 2005. 
20. Imade, M.; Fukuyama, S.; Zhang, L.; Wen, M.; Yokogawa, K. Hydrogen environment embrittlement of SCM440 steel in high pressure hydrogen at room temperature. J. Jpn. Inst. Met. 2005, 69, 190-193. [CrossRef]

21. Walter, R.J.; Chandler, W.T. Influence of hydrogen pressure and notch severity on hydrogen-environment embrittlement at ambient temperatures. Mater. Sci. Eng. 1971, 8, 90-97. [CrossRef]

22. Jewett, R.P.; Walter, R.J.; Chandler, W.T.; Frohmberg, R.P. Hydrogen Environment Embrittlement of Metals. In NASA-CR-2163; National Aeronautics and Space Administration: Washington, DC, USA, 1973; p. 238.

23. Walter, R.J.; Chandler, W.T. Influence of Gaseous Hydrogen on Metals-Final Report. In NASA-CR-124410; National Aeronautics and Space Administration: Huntsville, AL, USA, 1973; p. 170.

24. Walter, R.J.; Chandler, W.T. Effects of high-pressure hydrogen on storage vessel materials. In NASA-R-6851; National Aeronautics and Space Administration: Huntsville, AL, USA, 1967; p. 180.

25. New Energy and Industrial Technology Development Organization (NEDO). 2010 Oil Refining Industry Security Measures Project. RED on Material Usage Standards Associated with Hydrogen Energy Utilization; National Institute of Advanced Industrial Science and Technology (AIST): Tsukuba, Japan, 2011.

26. Han, G.; He, S.; Fukuyama, S.; Yokogawa, K. Effect of Nickel Equivalent on Hydrogen Environment Embrittlement of Austenitc Stainless Steels at Low Temperatures. Acta Mater. 1998, 46, 4570-4599. [CrossRef]

27. Fukuyama, S.; Zhang, L.; Yokogawa, K. Development of materials testing equipment in high pressure hydrogen and hydrogen environment embrittlement of austenitic stainless steels. J. Jpn. Inst. Met. 2004, 68, 62-65. [CrossRef]

28. Caskey, G.R. Hydrogen Compatibility Handbook for Stainless Steels. In Report DP-1643, E.I. du Pont de Nemours E Co; Savannah River National Laboratory: Aiken, SC, USA, 1983; p. 160.

29. Michler, T.; Yukhimchuk, A.A.; Naumann, J. Hydrogen environment embrittlement testing at low temperatures and high pressures. Corros. Sci. 2008, 50, 3519-3526. [CrossRef]

30. Clark, W.G. Effect of temperature and pressure on hydrogen cracking in high strength type 4340 steel. J. Mater. Energy Syst. 1979, 1, 33-40. [CrossRef]

31. Fukuyama, S.; Yokogawa, K.; Araki, M. Fatigue Crack Growth of SNCM439 Steel in High Pressure Hydrogen at Room Temperature. J. Soc. Mater. Sci. Jpn. 1985, 34, 709-714. [CrossRef]

32. Matsuoka, S.; Matsunaga, H.; Yamabe, J.; Hamada, S.; Iijima, T. Various strength properties of SCM435 and SNCM439 low-alloy steels in $115 \mathrm{MPa}$ hydrogen gas and proposal of design guideline. Trans. JSME 2017, 83, 1-20.

33. An, T.; Peng, H.; Bai, P.; Zheng, S.; Wen, X.; Zhang, L. Influence of hydrogen pressure on fatigue properties of X80 pipeline steel. Int. J. Hydrogen Energy 2017, 42, 15669-15678. [CrossRef]

34. Miyamoto, T.; Matsuo, T.; Kobayashi, N.; Mukaie, Y.; Matsuoka, S. Characteristics of fatigue life and fatigue crack growth of SCM435 steel in high-pressure hydrogen gas. Trans. Jpn. Soc. Mech. Eng. A 2012, 78, 531-546. [CrossRef]

35. Nelson, H.G. Hydrogen-induced slow crack growth of a plain carbon pipeline steel under conditions of cyclic loading. In Proceedings of the 2nd International Conference on Effect of Hydrogen on the Behaviour of Materials, Moran, WY, USA, 7 September 1975; Thompson, A.W., Bernstein, I.M., Eds.; The Metallurcical Society of AIME: New York, NY, USA, 1976; pp. 602-611.

36. Walter, R.J.; Chandler, W.T. Cyclic-load growth in ASME SA-105 grade 2 steel in high-pressure hydrogen at ambient temperature. In Proceedings of the Effect of Hydrogen on Behavior of Materials, Moran, WY, USA, 7 September 1975; Thompson, A.W., Bernstein, I.M., Eds.; AIME: Moran, WY, USA, 1975; pp. 273-287.

37. Matsuoka, S.; Takakuwa, O.; Okazaki, S.; Yoshikawa, M.; Yamabe, J.; Matsunaga, H. Peculiar temperature dependence of hydrogen-enhanced fatigue crack growth of low-carbon steel in gaseous hydrogen. Scr. Mater. 2018, 154, 101-105. [CrossRef]

38. Yamabe, J.; Yoshikawa, M.; Matsunaga, H.; Matsuoka, S. Effects of hydrogen pressure, test frequency and test temperature on fatigue crack growth properties of low-carbon steel in gaseous hydrogen. Procedia Struct. Integr. 2016, 2, 525-532. [CrossRef]

39. Yamabe, J.; Matsunaga, H.; Furuya, Y.; Hamada, S.; Itoga, H.; Yoshikawa, M.; Takeuchi, E.; Matsuoka, S. Qualification of chromium-molybdenum steel based on the safety factor multiplier method in CHMC1-2014. Int. J. Hydrogen Energy 2015, 40, 719-728. [CrossRef]

40. Ogawa, Y.; Birenis, D.; Matsunaga, H.; Thøgersen, A.; Prytz, Ø.; Takakuwa, O.; Yamabe, J. Multi-scale observation of hydrogeninduced, localized plastic deformation in fatigue-crack propagation in a pure iron. Scr. Mater. 2017, 140, 13-17. [CrossRef]

41. Ogawa, Y.; Birenis, D.; Matsunaga, H.; Takakuwa, O.; Yamabe, J.; Prytz, Ø.; Thøgersen, A. The role of intergranular fracture on hydrogen-assisted fatigue crack propagation in pure iron at a low stress intensity range. Mater. Sci. Eng. A 2018, 733, 316-328. [CrossRef]

42. Birenis, D.; Ogawa, Y.; Matsunaga, H.; Takakuwa, O.; Yamabe, J.; Prytz, Ø.; Thøgersen, A. Interpretation of hydrogen-assisted fatigue crack propagation in BCC iron based on dislocation structure evolution around the crack wake. Acta Mater. 2018, 156, 245-253. [CrossRef]

43. Ogawa, Y.; Umakoshi, K.; Nakamura, M.; Takakuwa, O. Hydrogen-assisted, intergranular, fatigue crack-growth in ferritic iron: Influences of hydrogen-gas pressure and temperature variation. Int. J. Fatigue 2020, 140, 105806. [CrossRef]

44. Nanninga, N.E.; Levy, Y.S.; Drexler, E.S.; Condon, R.T.; Stevenson, A.E.; Slifka, A.J. Comparison of hydrogen embrittlement in three pipeline steels in high pressure gaseous hydrogen environments. Corros. Sci. 2012, 59, 1-9. [CrossRef] 
45. San Marchi, C.; Somerday, B.P.; Nibur, K.A.; Stalheim, D.G.; Boggess, T.; Jansto, S. Fracture and fatigue of commercial grade api pipeline steels in gaseous hydrogen. In Proceedings of the ASME 2010 Pressure Vessel and Piping Conference (PVP 2010), Bellevue, WA, USA, 18-22 July 2010; pp. 2010-25825.

46. San Marchi, C.; Somerday, B.P.; Nibur, K.A.; Stahlheim, D.G.; Boggess, T.; Jansto, S. Fracture Resistance and Fatigue Crack Growth of X80 Pipeline. In Proceedings of the ASME 2011 Pressure Vessel and Piping Conference (PVP 2011), Baltimore, MA, USA, 17-21 July 2011; ASME Press: Baltimore, MA, USA, 2011.

47. Cialone, H.J.; Holbrook, J.H. Sensitivity of steels to degradation in gaseous hydrogen. In ASTM STP 962; Raymond, E.L., Ed.; ASTM International: Philadelphia, PA, USA, 1988; pp. 134-152.

48. Briottet, L.; Moro, I.; Lemoine, P. Quantifying the hydrogen embrittlement of pipeline steels for safety considerations. Int. J. Hydrogen Energy 2012, 37, 17616-17623. [CrossRef]

49. Vehoff, H. Hydrogen related material problems. In Hydrogen in Metals III. Topics in Applied Physics, Vol 73; Wipf, H., Ed.; Springer: Berlin/Heidelberg, Germany, 1997; pp. 215-278.

50. San Marchi, C.; Michler, T.; Nibur, K.A.; Somerday, B.P. On the physical differences between tensile testing of type 304 and 316 austenitic stainless steels with internal hydrogen and in external hydrogen. Int. J. Hydrogen Energy 2010, 35, 9736-9745. [CrossRef]

51. San Marchi, C.; Somerday, B.P.; Tang, X.; Schiroky, G.H. Effects of alloy composition and strain hardening on tensile fracture of hydrogen-precharged type 316 stainless steels. Int. J. Hydrogen Energy 2008, 33, 889-904. [CrossRef]

52. San Marchi, C.; Somerday, B.P. Effects of High-Pressure Gaseous Hydrogen on Structural Metals. SAE Technical Paper 2007-01-0433; SAE: Warrendale, PA, USA, 2007.

53. Hurtado Noreña, C.; Bruzzoni, P. Effect of microstructure on hydrogen diffusion and trapping in a modified $9 \% \mathrm{Cr}-1 \% \mathrm{Mo}$ steel. Mater. Sci. Eng. A 2010, 527, 410-416. [CrossRef]

54. Díaz, A.; Cuesta, I.I.; Rodríguez, C.; Alegre, J.M. Influence of non-homogeneous microstructure on hydrogen diffusion and trapping simulations near a crack tip in a welded joint. Theor. Appl. Fract. Mech. 2021, 112, 102879. [CrossRef]

55. Krom, A.H.M.; Koers, R.W.J.; Bakker, A.D. Hydrogen transport near a blunting crack tip. J. Mech. Phys. Solids 1999, 47, 971-992. [CrossRef]

56. Wang, Y.; Li, X.; Dou, D.; Shen, L.; Gong, J. FE analysis of hydrogen diffusion around a crack tip in an austenitic stainless steel. Int. J. Hydrogen Energy 2016, 41, 6053-6063. [CrossRef]

57. Wu, X.Q.; Kim, I.S. Effects of strain rate and temperature on tensile behavior of hydrogen-charged SA508 Cl.3 pressure vessel steel. Mater. Sci. Eng. A 2003, 348, 309-318. [CrossRef]

58. Dadfarnia, M.; Martin, M.L.; Nagao, A.; Sofronis, P.; Robertson, I.M. Modeling hydrogen transport by dislocations. J. Mech. Phys. Solids 2014, 78, 511-525. [CrossRef]

59. Xing, X.; Cheng, R.; Cui, G.; Liu, J.; Gou, J.; Yang, C.; Li, Z.; Yang, F. Quantification of the temperature threshold of hydrogen embrittlement in X90 pipeline steel. Mater. Sci. Eng. A 2021, 800, 140118. [CrossRef]

60. Vesely, E.J.; Jacobs, R.K.; Watwood, M.C.; McPherson, W.B. Influence of strain rate on tensile properties in high-pressure hydrogen. In Hydrogen Effects in Materials; Thompson, A.W., Moody, N.R., Eds.; The Minerals, Metals \& Materials Society: Moran, WY, USA, 1996; pp. 363-374.

61. Current status of round-robin tests for hydrogen material compatibility. In Proceedings of the 6th Meeting of the Informal Working Group on GTR No.13 (Phase 2), Tianjin, China, 18-20 June 2019. 